\title{
UNDERSTANDING MOBILE GOVERNMENT SUCCESS IN AN ARAB COUNTRY: FINDINGS FROM A QUALITATIVE STUDY
}

\author{
Kamel Rouibah, College of Business Administration, Kuwait University, krouibah@cba.edu.kw \\ Hasan Qurban, College of Business Administration, Kuwait University, hqurban@cba.edu.kw \\ Nabeel Al-Qirim, College of IT, United Arab Emirates University, Nalqirim@uaeu.ac.ae \\ Ali Tarhini, Sultan Qaboos University, ali.tarhini@hotmail.co.uk
}

\begin{abstract}
Research about end-user acceptance of information systems and electronic government has long been a popular topic in information system. Unlike previous studies which focused mainly on e-government based on a quantitative approach in investigating what influences individuals to use and continue using electronic government, this study focuses on mobile government in a developing Arab country. It uses a qualitative approach based on the information success model of Delone and Mclean (2003) and a modification of Rouibah et al. (2015). This study is part of a large project that aims to develop an Electronic Government Success Model (EGSM). Open-ended interviews were conducted with a diverse sample of 81 individuals in Kuwait composed of students, employees, job seekers and retired people. Results revealed that factors of the model of Rouibah et al. (2015) influence the use and continuous use of mobile government in terms of quality attributes (information, system, and service), perceived value, and perceived satisfaction. In addition, new factors were identified to influence mobile government, including trust factors (trust in e-government gate, trust in internet technology, propensity to trust, and trust in public government institutions), risk perceptions (security and financial risk, privacy risk perceptions, time risk perception), attractiveness of the alternative, lack of awareness and design esthetic. These findings have the implication of advancing mobile government acceptance and research to pursue a validation of the new model using a quantitative approach.
\end{abstract}

Keywords: electronic government, mobile government, factors of adoption, qualitative data, perceived value, trust, risk, information success model

\section{INTRODUCTION}

E-government is "the use of information and communication technologies, and particularly the internet, as a tool to achieve better government" (OECD, 2003). E-government is thus the use of these technologies to improve the activities of public sector organizations and allows online services (including electronic information and electronic transactions) to be available to different stakeholders. The advancement of e-government has been driven drastically through the avenue of Internet technology. It is increasingly recognized as a key facilitator for transforming public governance.

Stakeholders is a broad name that encompasses people living in a country (regardless of whether they are citizens or residents), employees, tourists, public institutions, private organizations, suppliers, customers, etc. Online services are depictured using an online gate that enables different stakeholders to access information from anywhere at any time using a single portal. The aim of the e-government initiatives is to improve the efficiency of governments and public institutions, reduce service cost and at times provide convenient delivery of services, increase stakeholder satisfaction of delivered services, and further improve interactions/communications of stakeholders with government institutions.

The quality of e-government initiatives is formally measured by international agencies that produce classifications all over the world according to set criteria and publish ratings annually. There are different types of e-government services that are evolving: G2C (government to citizens), G2G (government to governments), G2E (government to employees), G2B (government to businesses), G2T (government to tourists), and G2NP (government to nonprofit organizations), etc. Among these applications, this study focuses on government to citizens (G2C) acceptance.

Research about end-user acceptance (vs. reject) including online services and e-government (Deakins et al., 2010; Alomari et al., 2014; Salem, 2016; Alzahran et al., 2017), has long been a popular topic in information system. In line with this stream, this study focuses on end-user acceptance of e-government for the following reasons. First, previous studies have shown that a lack of individual acceptance of information system and online system is a significant obstacle to the success of these systems (Delone and McLean, 2003; Rouibah, 2008), which makes end-user adoption the backbone in determining the success (vs. failure) of new information system projects (Davis et al., 1993). Second, in addition, lack of individual use of these new technologies make these projects useless and may lead to budget cut; 
therefore, organizations in charge of e-government strive to boost acceptance and continuous use by end-users. Third, despite huge investments, e-government initiatives continue to fail to achieve their expected return on investment (United Nations, 2010). Most internet users are still reluctant to use and interact with e-government services (Harfouche and Robbin, 2012); even though they participate in social networking sites, use e-commerce websites, and perform ebanking transactions, they hesitate to use the internet to communicate with public authorities. Fourth, few qualitative studies have investigated the main factors relevant to the adoption of e-government by citizens in the Middle East countries (Alomari et al., 2014). Except Zhao et al. (2012) and Alomari et al. (2014), most of the past studies (AlAwadhi \& Morris, 2008; Alawneh et al., 2013; Alzahran et al., 2017) focused on approaching e-government adoption by end-users using quantitative studies, which cover the e-government acceptance from the researcher's perspective and not from the perspective of individuals and end-users themselves. For example, the literature review on e-government by Alzahran et al. (2017) that covered 24 studies showed that 18 were qualitative studies, only one was qualitative, while 4 studies were mixed studies. Accordingly, qualitative studies are lacking, which require additional studies to uncover e-government from the perspective of end-users.

Therefore, this study aims to fill in the above gap and answers the following two questions using a qualitative study: What factors influence the acceptance of mobile government by individuals in Kuwait and what factors may inhibit such acceptance?

\section{LITERATURE REVIEW}

The literature review carried out by the researchers shows the followings observations and pitfalls.

First, our literature review shows that e-government studies focused on different issues. Some studies focused on literature review (Salem, 2016; Alzahran et al., 2017), and the role of trust in e-government (Carter and Belanger, 2005; Srivastava and Teo, 2005; Sang et al., 2009; Shalini, 2009; Wang and Lo, 2010; Kurfalı et al., 2017; Warkentin et al., 2018). Others focused on factors that affect mobile government (Alssbaiheen and Love, 2015), citizens' adoption of egovernment (Salem, 2016; Alzahrani et al., 2017; Kurfalı et al., 2017), employees' adoption of e-government (Al-Busaidy and Weerakkody, 2009), obstacles of e-government adoption (Harfouche and Robbin, 2012), critical success factors for adoption (Ziemba et al., 2016), continuous use of e-government (Hong et al., 2017, Veeramootooa et al., 2018), current use in terms of types of e-government use (Nam, 2014), measures of e-government sophistication and comparison of e-government impact across countries (China, New Zealand, Oman, and the United Kingdom) (Deakins et al., 2010).

Second, the literature review also shows that different theoretical models were used to investigate either citizens or employees adoption of e-government. For example, the literature review of Alzahran et al. (2017) showed 8 studies used Technology Adoption Model, 3 used the Diffusion of Innovation Theory, one study used the Theory of Planned Behavior, and only two studies used the Delone and McLean success model. Others also used the Social Cognitive Theory (Rana and Dwivedi, 2015) and UTAUT (Kurfalı et al., 2017). Accordingly, this study will use the Delone and Mclean as a framework that guides this qualitative study.

Third, with regard to e-government studies in the Arab region, several studies were conducted. These studies focused on different issues such as: citizen perceptions of barriers to e-government adoption in Jordan using qualitative study (Alomari et al., 2014), user satisfaction from e-government services in Jordan (Alawneh et al., 2013), key issues and challenges in e-government development in UEA (Zhao et al., 2012), inhibitors and enablers of public e-services in Lebanon (Harfouche and Robbin, 2012), individuals' intention to use e-government in Kuwait using UTAUT (AlAwadhi and Morris, 2008), critical success factors affecting e-government in Oman (AlShihi, 2006; Ziemba et al., 2016), impact of e-government in Oman (Deakins et al., 2010), and factors influencing e-diplomacy implementation in Qatar using interpretive structural modeling (Al-Muftaha et al., 2018). However, only one study focuses on mobile government in Saudi Arabia (Alssbaiheen and Love, 2015)

Third, although end-user perceptions of the risks of adopting e-government have been studied by many Western researchers (e.g. Rana et al., 2015; Ziemba et al., 2016; Veeramootoo et al., 2018) and Arab researchers (Abu-Shanab, 2017), risk has only been included as a single construct, which fails to reflect the real characteristics of perceived risk and explains why individuals still resist using e-government.

Fourth, while privacy was over-investigated in e-commerce, few studies have investigated its effect on e-government adoption. Privacy is becoming an important construct in information technology adoption studies after June of 2013 when Edward Snowden, an information technology contractor for the US NASA, started revealing the capability of the world's intelligence agencies in monitoring online communications and revealed the story of stolen classified 
documents that violate individual privacy all over the world (Preibusch, 2015); thus the popularity of privacy in information system research increased (Pieron and Smith, 2017).

To provide a deeper understanding of the adoption of mobile government (use and continuous use), we carried out a more in-depth and qualitative study of the factors of such adoption guided by the information system success model of Delone and McLean (2013) and the modification provided by Rouibah et al. (2015) which are explained next.

\section{The Delone and Mclean model and its extension for understanding mobile government}

Even though e-government research on acceptance (intention to adopt, use and continuous use) has focused on different models and factors that affect acceptance (Danila and Abdullah, 2014; Salem, 2016; Alzahran et al., 2017), it is surprising to note that these studies are dominated by TAM and its variations while the information success model (DeLone and McLean, 2003) received less attention in e-government studies although it has been extensively investigated in many contexts (see literature review done by Rouibah et al., 2015). Compared to TAM, fewer studies have attempted to apply the information success model to e-government (Wang \& Liao, 2008; Rana et al., 2015; Veeramootoo et al., 2018). However, these studies are not comprehensive and lack integration of other factors that influence mobile government. Delone and McLean (2003) is comprehensive, has been carefully developed over time, and has been validated extensively (see literature review in Rouibah et al., 2015). First, Delone and McLean (2002) proposed a system success model with six success dimensions: system quality, information quality, use/intention to use, user satisfaction, and net benefits. This model was further improved by Delone and McLean (2003) to include service quality.

According to Rouibah et al. (2015), the reason few researchers applied this model to the wireless environment (including e-government, and taking into account that Rouibah et al., 2015, focused on e-commerce) is that certain key differences exist between general information system and online systems, which makes the extension to the wireless environment challenging: (1) The usage purpose is different because end-uses use mainly to carry electronic services and electronic transactions, whereas organizational employees use general information system primarily for work purposes. (2) Employees are consistent in their information system in the workplace, whereas online users can be unpredictable, especially if their satisfaction has not been achieved. (3) The context is different because organizations use a context-specific information system to support their business, whereas e-government and mobile app interact with their customers using the same product and interfaces. Consequently, understanding e-government success needs a new theory distinct from that, which explains information system success.

In addition, moving beyond typical Western studies that applied the Delone and Mclean model (2003) to an application in a developing context require conducting a qualitative study to show how the contextualization of Western theories may work in another context as suggested by previous studies. For example, Hong et al. (2014) identified three strategies during the contextualization: (i) identify a general theory (in this study the success model of Delone and McLean) (ii) add/delete core constructs to fit a specific context (iii) and incorporate new contextual factors.

While a sub-set of e-government studies focused on the information system model, they are silent on how the contextualization, as described above, was achieved, what new components of this model are to be added, and how they are measured since items were reused from adoption studies without a careful assessment of the context and without a rationale for the selected factors.

This study focuses on mobile government (noted here m-Government) by providing clarifications to these issues using the context of an electronic government portal in an Arab country.

\section{E-government use in Kuwait (http://www.e.gov.kw) and its mobile app (EGOVKW)}

The government of Kuwait has started efforts to create electronic government since 2000 to improve its services and achieve the highest levels of efficiency and transparency in presenting government services to the Kuwaiti population. It also aims to achieve the ultimate goal of e-Kuwait within the overall framework of the strategic goals of the state. The electronic government gate of Kuwait was developed by the Central Agency for Information Technology-CAIT (www.cait.gov.kw) in 2006. This online gate connects 62 public institutions in Kuwait in a secured network using CINET (www.cinet.com.kw), which provides a wide range of services, total of 1902 services that include both information services (993) and electronic transactions (909). These are relevant to different beneficiaries, including citizens, residents, employees, government institutions, the business sector and visitors. For example, citizens and residents can pay their bills to the Ministry of Electricity and Water, and Ministry of Communications using the online payment system (also known as Tasdeed). Tourists can know about Kuwait in general, political and economic news as well as its weather. Business people may use it to get more information about Kuwaiti commerce environment, rules, regulations and trades. In addition to this, the online portal contains links to most governmental and non-governmental sites. 
The e.gov.kw gate includes several categories to make it easy for visitors to find relevant information. The first one includes the latest projects in Kuwait and the latest important news. The second category includes a section that enables end-users to navigate through the public ministries. The third one shows all the electronic services of the portal. In the fourth category a box enables end-users to write visitors' opinions. It also includes a section related to "IT awareness" which aims to increase awareness among the society with regard to security threats and includes links to many videos available on YouTube.

Besides the website, CAIT also designed a mobile application (EGOVKW), which is available to download from leading platforms (Google Play and Apple store). This mobile app is compatible with different mobile devices. The app provides this information 24/7 and allows end-users to access all e-services and conduct online payment transactions, which are also available on the e.gov.kw gate. A few of the content and services provided by the mobile app includes portal statistics (total number of visitors, number of page views, number of new visitors, total amount of e-payments, average page views, number of e-payment transactions, and average time a visitor stays on site), electronic payment system (Tasdeed), IT awareness, and government services (ex: Public Authority for Housing Welfare, Public Authority for Special needs, etc.). The app is regularly updated. If any end-users face problems, the app provides a contact email and a call center using a phone number (that can be used inside and outside of Kuwait). Social networking (e.g. Twitter, Facebook, and Instagram) FAQs, and a Contact Us page are available to enable the end-user may seek support from CAIT call center.

The app consists of buttons for navigation that can guide and take end-users to the desired section. Sections are interactive and listed with sub-sections which, when clicked, can take end-users to the relevant website, among the 62 public institutions in Kuwait connected to the mobile app.

\section{RESEARCH METHODOLOGY}

This study used a qualitative approach to investigate the drivers and problems toward m-Government using a sample of variety of end-users and potential users. Qualitative data was analyzed using an interpretive research methodology (Klein \& Myers, 2001), which allows useful insights into information systems phenomena. This methodology has been used in areas of information systems research such as social commerce (Rouibah and Al-Qirim, 2017). This study is part of a large project that uses "mixed research method" (Hong et al., 2014) and combines both qualitative and quantitative data collection to shed more light on factors that influence m-Government adoption. However, in this study we present only the qualitative data and its results.

\section{Sample and procedure of data collection}

The population consists of all adults in Kuwait who are end-users or potential or real end-users of the official egovernment gate in Kuwait (e.gov.kw) along with its mobile application (EGOVKW). This study targets a variety of end-users. The sample included 81 Kuwaiti citizens including undergraduate students (35) and post-graduate students (15), un-employed housewives (2), employees (23), job seekers (2), and retirees (4) of both genders toward their mGovernment acceptance (intention to use, use, and continuous use). Undergraduate students were registered in two MIS courses, "introduction to MIS" and "introduction to e-commerce", while the post-graduate students were registered in the "e-government" course. Of the 81 participated in our survey. Of the 81 participants, $29.63 \%$ were male and $70.37 \%$ were male. The minimum age of participants was 18 years, and the maxim 60 years with an average of 34 years.

The study consisted of interviews in which respondents were asked to state whether they are aware of e.gov.kw gate, whether they use it, and if they did not use it before, were first introduced to the e-government gate (and its mobile app), got familiarized with it (in terms of its functions and how it works), and then list as much as they can in a free format: (i) What factors affect their intention to use or not to use or continue to use the mobile application? (ii) What are the potential problems they may face when using the mobile app? The minimum time of interviews was 5 minutes, the maximum 15 minimum and an average time of 8 minutes.

Information collected during interviews included: (i) demographic information about the Interviewee (gender); (ii) position of the interviewee (student, employee, retiree, or job seeker "not working"); (iii) duration of interview; (iv) the main drivers/obstacle toward m-Government adoption/use/ continuous use in a free format as quoted by interviewees. A total of 81 interviews were conducted. Interviews were in Arabic and English languages, recorded, transcribed later for and analyzed by the researchers of this study. 


\section{RESULTS}

\section{What factors influence mobile government in Kuwait (adoption, use and continuous use)?}

The analysis of the qualitative interviews showed the applicability of the Mclean and Delone model with new and additional factors that affect m-Government acceptance by the 81 participants. This study also identifies new items to measure the identified factors. The research findings and factors are grouped and categorized by themes, taking into consideration the Delone and McLean model and improvement of Rouibah et al., (2015).

\section{1-Perceived value}

Perceived value refers to the difference between the positive and the negative impacts of the m-Government on endusers (DeLone and McLean, 2003). It results from an evaluation of the relative rewards (value derived from $\mathrm{m}$ Government) and sacrifices by end-users (time to learn the mobile app). As expected by the information success model (Mclean and Delone, 2003; Rouibah et al., 2015) this construct was extensively mentioned by interviewees as an important factor that influences end-users toward m-Government adoption. Findings of our study reveal six items to measure what perceived value means in m-Government (among them 5 new items for the first time):

The following are quotations of end-user-perceived value when using the mobile app:

Government in pocket: "It is a mobile government in the pocket and I can use it along the day (24 hours a day). [Employee]

One gate to pay for government transactions: "It is relevant and useful since I can use one online gate to pay for my transactions anytime (e.g. pay electricity and water bills as well as fines) and services booking (e.g. booking a dentist appointment, buying tickets online, registering for academic aptitude tests and a variety of other transactions with a simple click) anywhere with the internet and I don't have to go to the government offices and ministries and lose my time." [Employee]

One gate to access a comprehensive set of electronic information and services: "It's very useful since it allows me to access 220 electronic services related to different public institutions, search for relevant information, and offers me rich content such as statistics, marriage DNA" [Student]. "It allows me to access a rich and diversified content of useful information." [Student]

One gate to allow communication with public institutions: "It allows individuals in Kuwait to communicate with the government institutions through social media and get the latest news about the new services offered by different public institutions and ministries." [Employee]

One gate to increase security awareness: "It allows me to increase my awareness about security issues through the posted videos and news". [Student]

One gate to saving time: "It delivers me good value so that I can save and print some of the required papers and fulfill them and give them all at once at the required public institution, so that I don't have to go to different ministries many times" [employee]. "It saves my time and effort and provides me with valuable information. [Student]

Therefore, the above findings corroborate with previous studies that used perceived value as components of the Delone and McLean model in e-government in terms of making transactions easier and saving the time of end-users (Wang \& Liao, 2008), extend studies that did not include it (e.g. Veeramootoo et al., 2018), and provide more insight into what perceived value means in the context of m-Government.

\section{2-System quality}

System quality is another key dimension that determines the success of a mobile app. It refers to the performance of the system in terms of usability, availability, reliability, adaptability and response time (DeLone \& McLean, 2003). It is an important construct in the information system success model of Delone and McLean. Participants described the functions of the mobile app according to the following functions: ease of use, availability, reliability, response time, navigation, and interactivity. Examples of participants' quotations with regard to their perception of EGOVKW includes the following system quality attributes.

Ease of use: "I downloaded the mobile app and I found it fast and easy to use" [student], "easy to pay for the bills" [student], "easy to use and reliable" [student], and "user-friendly" [student]. 
Learning effort: "The first time I used the mobile app was to pay a fine accident. It was difficult to use and to complete the transaction. However, with time I got used to the system [student].

Availability: "I can find information, news, statistics, contact information and social media communication on the mobile app which is available 24 hours a day" [student].

Reliability: "Personally I tried booking an appointment through the mobile app and found it is very useful and reliable" [student].

Navigation: "Navigation steps of the app are clear to the end-user and shown down the screen. They include five sections: call us, about the gate, news, communication, statistics. As for the home page, it provides the user choices to make electronic transaction" [student].

Interactivity: "The app is interactive since it allows the users to make transactions like paying water and electricity bills or for traffic violations" [student] and "is fairly interactive (there is a two-way flow of information between the app and the customers" [student].

\section{3-Information quality}

It refers to the desirable characteristics of the system output (Rouibah et al., 2015). It is an important construct in the information system success model of Delone and McLean. Information quality refers to quality attributes such as reliability, up to date and completeness, precision, timeliness, comprehensiveness, accuracy and understandability.

Quotations of interviewees include the following information quality attributes related to EGOVKW.

Reliability: "Information provided in the app is reliable and up to date" [student].

Up to date and completeness: "The app provides up-to-date information" [employee] and "There is an icon with the latest news which is up to date; also they show statistics of the application traffic" [student].

Precision: "It provides precise information about the required information I need" [employee].

Timeliness: "the mobile app is updated regularly [student].

Comprehensiveness: "The information provided is large in scope and covers diverse subjects" [student].

Accuracy: "Information provided in the app is accurate, important, helpful, meaningful and updated" [student].

Understandability: "The app is filled with information that is easy to understand" [student].

Therefore, the above attributes corroborate with previous findings of application of information system success model in e-government which used some of these items (Veeramootoo et al., 2018) but our identified items go beyond those applied in e-government studies (Wang and Liao, 2008) which used only a few attributes (precision, comprehensiveness, and up-to date).

\section{4-Service quality}

It refers to the quality of the overall support delivered to end-users (Rouibah et al., 2015) when they interact with the support provided by the e.gov.kw. It is an important construct in the information system success model of Delone and McLean. Participants reacted with regard to this construct in terms of the following four quality attributes: reliability of service, assurance, responsiveness and empathy. Reliability measures the extent to which the CAIT attempts to improve the information services provided to end-users. Assurance refers to the ability of the information system (IS) staff of CAIT to build users' confidence. Responsiveness measures the extent to which the IS staff are willing to help end-users and provide prompt services when needed. Empathy measures the personal attention and care provided by the CIS staff when answering end-users of the mobile app about complaints and problems.

Quotations of interviewees who were happy about their experiences include the following service quality attributes related to EGOVKW.

Reliability of service: "the mobile app has an icon for all the social media available to be used by end-users to request help and support" [student]. "They have a call center that replies quickly to all phone calls. But other forms of contact may take some time to reply to (ex: email)" [student]. 
Assurance: "Contact information is available which includes number to be used in Kuwait and abroad which I used and it works" [student].

Responsiveness: "There is a call center to answer end-users' complains, and employees picked up immediately when I called them and there was no call waiting" [student].

Empathy: "Phone operators are very patient and willing to explain every detail and inquiry about the app with care and respect to the user" [employee].

While some end-users found the level of service quality at their level of expectations, negative feedback focused on two issues.

Responsiveness problem: "EGOVKW has no immediate responsiveness to customers, it has no live chat when I tried to reach them" [student].

Assurance problems: "The call center operators do not have all the information regarding the app; for example, when I called them they knew that it is updated regularly but they do not know when or how long it takes" [employee].

The above findings show that the four dimensions of SERVQUAL, with the exclusion of tangibility, were found to be significant predictors of service quality in mobile government, which confirms previous studies (e.g. Veeramootoo et al., 2018).

\section{5- Trust perceptions}

This construct is becoming one important factor toward adoption of technologies in online environments. Because of risks, people need to develop trust to lessen fear perceptions. Customer trust refers to the consumers' belief that the online transactions will be processed in accordance with their expectations (Rouibah et al., 2016). Trust is a complex construct that has many facets as shown by prior studies (Rouibah et al., 2016). In line with these studies, our interviews have shown that this construct includes different sub-constructs such as trust of the e-government gate, trust of internet technology, propensity to trust, trust in public government, Propensity to trust and Trust of third-party Seal.

Many respondents have expressed their trust perceptions of the e-government when they conduct online transactions such as the following:

Trust of the e-government gate and mobile app (EGOVKW): "I trust e.gov.kw and I feel comfortable while using it" [housewife]. "She does not trust any website on the internet; however, she trusts any website related to the government because she thinks that the government supports e.gov.kw with powerful protection programs" [student].

Trust of internet technology: "My mother said that she does not trust the internet, and she will not pay by the website because she can go by herself and complete all her paper transactions" [Housewife]. "I do not trust providing sensitive and personal data over internet technology when paying online" [retiree].

Trust in public institutions: "I trust e.gov.kw because it is a government website and I trust that it protects me well" [employee] "The service is provided by a trustworthy source which is the Central Agency for Information Technology (CAIT) and it is very reliable and it is performed dependably and as promised".

Propensity to trust: “At the beginning, I followed the payment process by visiting the government agencies to be sure the online payment transactions are done, but after a while I accepted the system and trust it, and I did not experience any problems with the system. However, I did not try the mobile app" [student]. "I believe the services provided by e.gov.kw are authentic and secured and I feel protected while paying my fines online" [student].

Trust of third-party seal: "I trust the e.gov.kw and its mobile app because it is fully reliable and secured since it includes the Third Party Seal logo 'GeoTrust' which was visible when I performed my payment transactions" [student].

Our finding thus partially support previous studies that conceptualized trust as a complex construct composed of trust of government and trust of internet (including Carter and Belanger, 2005; Srivastava and Teo, 2005; Wang and Lo, 2010; Kurfalı et al., 2017). However, our results contrast with those that analyzed trust as a single component, "trust in egovernment services" (Sang et al., 2009; Shalini, 2009; Abu-Shanab, 2017; Warkentin et al., 2018). In fact, the study of 
Carter and Belanger (2005) was among the first research in the context of e-government while Srivastava and Teo (2005) discussed the component of trust in e-government and replaced "trust of internet" with "trust on technology", which is a broader term. In addition, our findings extend the findings of previous studies to encompass three other dimensions of customer trust: trust of public institutions, propensity to trust, and trust of Third-Party Seal.

\section{6-Risks and privacy perception}

Perceived risk refers to the subjective probability in the end-user's eyes that his or her personal or financial information will not be shown, saved, and/or stolen during online transaction and storage by outside parties (Flavian and Cuinaliu, 2006). Also, it is the negative consumer's perception that the online service vendor will not fulfill his security requirements (Rouibah et al., 2016). Risk perception is related to a lack of knowledge of the service provider's procedures and the risks associated with the internet in terms of insecurity of transactions and the potential risks associated with theft of confidential data transactions. This construct has several dimensions as theorized by Jacoby and Kaplan (1972) and empirically validated by Lee (2009), including financial, security, privacy, performance, social and time risk. Till date, there is no common universally accepted definition of privacy. For example, Westin (1967) described privacy as the "ability for entities involved in a transaction to determine for themselves when, how, and to what extent information about them is communicated to others." While Pieron and Smith (2017) described it in a simplified manner, as "the absence of intrusion". Gosten and Nass (2009) defined privacy as safeguarding personal information against unauthorized or unjustified disclosure. Privacy is also a complex concept that embraces many dimensions and elements, encompassing "the right to be left alone" (Warren and Brandeis 1890) and human dignity (Bloustein 1964). In this study and following Lee (2009), we define privacy risks as "potential loss due to fraud or a hacker compromising the security of an end-user account". Privacy risks may be compromised by hacker phishing attacks. Hackers used this new technique to attempt to fraudulently acquire sensitive information, such as usernames, passwords and credit card detail information, and sending this information in fraudulent e-mails that look like they come from a legitimate and trusted entity (e.g. NBK, a famous bank in Kuwait). A phishing attack takes place when a user receives a fraudulent email (often referred to as a spoof email) representing a trusted source that leads them to an equally fraudulent website that is used to collect personal information and thus violate end-user privacy.

Quotations of interviewees about their risk perceptions include the following three dimensions.

Security and financial risk perceptions: "When I used the system for the first time and paid I felt at risk and I can lose my money because I have not paid before through the Internet." [Student] "There may be some risks associated with the m-Government use because the Internet is not secured at 100\% when I conduct online transactions as well as share personal information." [employee]

Privacy risk perceptions: "I do trust the e-government gate and pay online. However, there is one thing I do not like. My data privacy can be violated. Everyone could know everything about me by just entering my civil ID which is very easy to get in Kuwait." [employee].

Time risk perception: "Except for online payment value, I can perceive that much of the information available in the mobile app can be found on Google; therefore searching and using the mobile app turns out to be losing of my precious time". [Employee]

While many interviewees expressed their fear when using the e.gov.kw and its mobile app, others did not express any fear risk perceptions: "I think that paying for online fines is not risky while using this mob app since it is a government website and well protected." [students] "Before I tried the system, I used to have a feeling of risk perception. However, now I don't." [student] "Transferring of any personal information from and/or to the e.gov.kw portal is highly protected using the latest suitable techniques of information security." [student]

The above finding shows that risk perception is a complex construct, which therefore corroborates with findings of recent studies in technology adoption that have investigated it dimension (Lee, 2009; Martin et al., 2014; Yang et al., 2015). However, our findings are richer and contrast with previous studies in e-government that have conceptualized risk as a single construct (e.g. Rana et al., 2015; Ziemba et al., 2016; Veeramootoo et al., 2018) and revealed that perceived risk is an impediment toward e-government adoption. Therefore, security assurance is needed to boost adoption (Abu-Shanab, 2017). Our findings also support a few Arab studies that found that a strong privacy protection influences intention to use e-government (Abu-Shanab, 2017).

\section{7- Satisfaction and intention to continue use}

Satisfaction is an individual perception that refers to the difference between expectation and real experience when using the e.gov.kw (Rouibah and Al-Qirim, 2016). The end-user feels satisfaction when experience exceeds his/her expectations, and leads to his/her dissatisfaction in the opposite case. Following results of past studies on the application 
of the information success model of Delone and Mclean, satisfaction was quoted by interviewees as another factor that influences customers' intention to adopt m-Government. Here are some of their quotations:

Overall satisfaction: Interviews revealed that many individuals were very satisfied with their experience with the system: "I am very satisfied and I had wished that many individuals in Kuwait would know about the site because it is very helpful." [employee] "I am satisfied with the information provided by the mobile app as well as the app quality, efficiency, effectiveness, and the whole online payment and online appointment reservation system." and I advise others "to use this integrated system that connects different public institutions" [student]. While other interviewees stated that "the system provided me with information I need when desired and the experience meets my expectations." [student] "I am very satisfied with the quality of this app. It is frequently updated and provides a wide range of services." [student] "I am very satisfied with the online payment Tasdeed service which allows me to pay my bills anywhere and anytime." [student]

The mobile app is less used compared to the website: Interviews also revealed that individuals use the website (e.gov.kw) more than the mobile app: "Through the interviews I did and the information I found about the e.gov.com, I discovered how the system functions and its benefit, and I think the next time I will definitely use it. In addition, during my interview I found that most of my interviewees use online system more than the app." [employee]

Intention to use: "I plan to use EGOVKW app in the future and pay my bills and get a dentist appointment." [student] "I did not use it before until I was introduced to it by a member of my family. Since that time, I am happy to use it so far; I will certainly use this app more often since it's greatly beneficial." [employee]

\section{8- Attractiveness of other alternatives}

This is a new construct that none of the previous e-government studies investigated. It refers to the characteristics available in a product/system other than the one in focus. This factor has received much attention in switching studies (e.g. Yan et al., 2015). It includes two steps: the comparison and the evaluation of the mobile app with other existing mobile apps that belong to other countries. Comparison refers to "the attitude end-users hold when they are comparing the mobile app with other systems either the online gate or other mobile apps of other countries" while evaluation refers to the end-user's attitudes before he becomes familiar with certain new technology.

Interviewees have cited this construct several times as a factor that pushes them away from using the mobile app. Some interviewees compared the Kuwaiti mobile app with the mobile app of Dubai by stating: "The mobile app of Dubai, also known as Mpay, is more design attractive and appealing than EGOVKU in Kuwait [post-graduate student]." Another one also supported this statement by saying, "When I compared the app with other apps (e.g. Dubai), I found it to be poorly designed, hard to navigate and less data-rich." [student] Another interviewee compared the number of languages available in Mpay and EGOVKW by saying "Mpay has more languages than EGOVKW'. Other interviewees compared the mobile app of Kuwait with the online e-government gate, "I prefer to use the website instead of the mobile app." [post-graduate student]

\section{9- Lack of awareness}

Awareness is an important driver towards m-Government acceptance. This construct refers to the trend awareness of being mindful of the existence of a technology that is recently becoming popular and is readily accepted in the market. Many interviewees have quoted that they did not know the existence of the online gate of and its mobile app until it was introduced by their kids who are students of the authors' study. Some of them pointed to the lack of publicity: "Kuwait provides many electronic websites, and they are full of important information and services. However, these are not famous and well-known, and there are many people who do not know about them because of the lack of advertisement". A similar idea was also stated by another interviewee "Citizens don't have awareness about the mobile app, and the ones who know about it don't prefer to reuse it because it's not user-friendly" [student]. Another one simply stated, "I have not heard of the mobile app before." [employee] This is reiterated by another interviewee who suggested advertising about it in schools, universities and public areas, "Many people I know do no use it because they don't know about its existence. I recommend advertising it more, so the public will know more how they may benefit from the mobile app." [student]

These findings support recent Arab studies conducted on e-government adoption in Jordan (Al-Jaghoub et al., 2010; Abu-Shanab, 2017) which found that low familiarity with e-government negatively and significantly influence its adoption of, and low level of e-government awareness is an obstacle toward adoption. 


\section{0- Expectation vs. conformation}

These two factors are derived from the expectation-confirmation theory. Expectations refer to one's beliefs about future events while confirmation is the discrepancy between a user's pre-adoption expectations and perceived experience performance (Oliver, 1980; Rouibah and Al-Hassan, 2019). If the expectations are higher than the real experience then the end-users will perceive dissatisfaction (Rouibah and Al-Hassan, 2019).

Some interviewees compared their expectation before using the mobile app with their real experience after they effectively used it and were disappointed. An interviewee said, "The content of EGOVKW has not met my expectations. It did not give me sufficient information as I need. For example, I tried to access the pages of the ministry of higher education and I have received a wrong message". Another interviewee stated, "During my search, EGOVKW did not offer me needed information. The information was not provided in a useful format. For some pages you could not zoom in or zoom out. You had to swipe to the left and right, and for some other pages also you had to rotate the phone, and still not all information will be presented in a clear format." [student] Another interviewee said, "I am not fully satisfied because the mobile app design is not attractive or user-friendly." [employee]. Such dissatisfaction perceptions led them to not planning to use the system: "I am not satisfied with the mobile app quality and overall I did not like the application experience, and I don't plan to reuse the app in the future. " [student]

However, others experienced more satisfaction since their experience surpassed their expectation. "I never knew that we could take a dentist appointment through the app. So, I took an appointment and it was instantly confirmed to me through SMS." [employee]

\section{1-Interface design and quality esthetic}

Many information studies have shown that esthetic and quality design is an important driver toward new technology adoption (e.g. Cyr, 2014; Hong et al., 2017). In line with these studies, our findings reveal that interface quality and its esthetics play an important role in the continuous use of $\mathrm{m}$-Government. This result is new in the e-government field since no study has investigated it before.

Some interviewees found the design of the mobile app is attractive and appealing. Interviewees have stated three attractive factors related to design and quality esthetic. The first one is related to its user-friendliness: "The mobile app is user-friendly and provides me with all I need." [student] Another interviewee stated, "The interface is very useful and simple." [Employee] The second one is related to the ease of navigation: "My mother said that it was easy to get information because the site was very simple and easy to understand." [employee] The third one is related to good interactivity: "The app provides an email, phone number e-payments, and appointment reservation through the app." [student]

However, other interviewees found many problems related to interface design. These are the problems they faced:

Problem of design navigation: "I had major problems accessing the app with my iPhone so I had to use my old android phone to access the app." [student]

Problem of interactivity: "The mobile app is not intelligent. For example, when I click on e-services and I want to go back there, it doesn't take me. It, however, redirects me to the homepage which bothers me because it does not provide end-users with their mostly checked-in category to save their time." [student]

Lack of search engine on the mobile app: "There is no search engine provided. The customers will have to spend more time scrolling up and down to find what they need." [student]

Poor reliability: “The design of the app is bad, sometimes it lags.” [Post-graduate student]

There is only one interface language: Many participants noted the absence of any language other than Arabic even though the online gate has English language "There is no language option in the app and website for understandability, which raises problem of understandability for people living in Kuwait who cannot understand Arabic." [student]

System reliability: “The system always freezes whenever I try to pay for online fees.” [employee]

In addition to studies that have looked into the effect of interface and quality design on e-government acceptance, our findings corroborate with recent studies (Hong et al., 2017) that examined the effect of content design continuous intention to use of the e-learning system and found that, if users are satisfied with the content design and interface design, they will perceive utility value, which translated into more intention to reuse. 


\section{CONCLUSIONS}

This study focused on determining the factors that influence the acceptance of mobile government (use and continuous use) in an Arab country.

\section{Research contributions}

Compared to previously existing knowledge on e-government research, this study has achieved three contributions. First, unlike the majority of studies that focused on e-government acceptance, this study is among the few initiatives that focused on m-Government acceptance using a qualitative approach. It helps to clarify factors that affect the acceptance of m-Government from the perspective of end-users and not from the researcher's perspective. Second, following the recommendations of Rouibah and Qirim (2017), we used a qualitative approach and used interviews as data collection method with a large sample (81 end-users with different backgrounds), which enabled us to provide a deep understanding about m-Government acceptance issues. And we succeeded in identifying 11 factors toward m-Government acceptance; for the first time, new constructs in $\mathrm{m}$-Government acceptance are represented here by the attractiveness of alternatives (comparison and evaluation) as well as sub-components of risk perceptions and trust perceptions. Third, this study succeeded in identifying a list of measures/indicators/factors for m-Government acceptance, which will be useful for the development and validation of a new Electronic Government Success Model that constitutes the second phase of this project. These results do confirm and extend the findings of previous empirical studies about e-government and m-Government, especially studies that applied the information system model (e.g. Wang \& Liao, 2008; Veeramootoo et al., 2018).

This study has revealed that Kuwait provides an online gate along with a mobile app for e-government services and transactions which are relevant and useful. However, there are many end-users who are not aware of their existence because of the lack of publicity. On the other hand there are other end-users who have trust issues (trust in the egovernment gate, trust of internet technology, propensity to trust, trust of the internet, and trust in public government). Other issues include risk perceptions (security and financial risk perceptions, privacy risk perceptions, and time risk) and problems with interface design, system reliability and navigation.

\section{Managerial implication}

The Kuwaiti government has made a huge investment to make the e-government gate and its mobile app available. However, return on investment cannot be achieved unless these tools are known, accepted and fully adopted by endusers. Therefore, the management of CAIT is encouraged to take into account the factors identified to increase awareness about CAIT (e.gov.kw and EGOVKW). They are also encouraged to undertake efforts to improve the mobile App needs identified in this study, especially in terms of interface design. There is a need to (1) add more languages for the mobile app as well as a search engine, (2) improve the design and interactivity so end-users can access the information with zoom-in and zoom out functions, (3) fix the server errors to guarantee the reliability and continuous availability of services for end-users, (4) check all videos to ensure security awareness are working and add Previous and Next buttons for these videos to ease end-user navigation. (5) They need also to improve the navigation design /interactivity; moving from one page to another from the same category in the mobile app means going back to the homepage, choosing the category again and scrolling up and down. (6) Lastly, adding a button to end-user review page would be a great jump toward improving this mobile app so that the visitors or end-users can post their comments about their experience after using it.

\section{Study limitations and future research perspectives}

While the study contributed to identifying 11 factors that impact m-Government acceptance in the Arab country of Kuwait, the study is still limited with regard to the nature of cause and effect between those factors. Accordingly, we are pursuing these efforts using a quantitative approach to develop an improved Electronic Government Information Success Model based on the factors identified in this study and validate it across cultures using PLS structural equation modeling to identify potential significant paths and create more generalizable results.

\section{ACKNOWLEDGEMENTS}

This research was funded by Kuwait University, Research Grant IQ 01/17. The author acknowledges the Research Administration Project for its support. 


\section{REFERENCES}

Abu-Shanab, E. A (2017). E-government familiarity influence on Jordanians' perceptions. Telematics and Informatics $34,103-113$

Akkaya, C., Obermeier, M. Wolf P., \& Krcmar H., (2010). Components of Trust Influencing eGovernment Adoption in Germany. International Conference on Electronic Government EGOV 2011: Electronic Government, 88-99.

AlAwadhi S., \& Morrirs, A. (2008). The Use of the UTAUT Model in the Adoption of E-government Services in Kuwait. Proceedings of the $41^{\text {st }}$ Hawaii International Conference on System Sciences.

Alawneh, A. Al-Refai, H. \& Batiha, K., (2013) Measuring user satisfaction from e-Government services: Lessons from Jordan. Government Information Quarterly, 30, 277-288.

Al-Busaidy, M. \& Weerakkody, V. (2009). E-government diffusion in Oman: a public sector employees' perspective. Transforming Government: People, Process and Policy, 3(4), 375-393.

Al-Muftaha, H. Weerakkodya, V. Ranab, N. P. Sivarajaha, U. \& Irani Z. (2018). Factors influencing e-diplomacy implementation: Exploring causal relationships using interpretive structural modeling. Government Information Quarterly [Forthcoming]

Alomari, M. K. Sandhu, K. \& Woods, P. (2014). Exploring citizen perceptions of barriers to e-government adoption in a developing country. Transforming Government: People, Process and Policy, 8(1), 131-150.

Alshawaf, A. R., Ahikari, A., \& Zhang, H. (2002). Information ethics: an investigation of different subcultures in a society. Review of Accounting and Finance, 1(3), 54-73.

Alssbaiheen, A. \& Love, S. (2015). m-Government Adoption in Saudi Arabia: Challenges and Opportunities. International Journal of Technology and Human Interaction, 11(3), 51-68.

Alzahrani, L. Al-Karaghouli, W. \& Weerakkody, W. (2017). Analysing the critical factors influencing trust in egovernment adoption from citizens' perspective: A systematic review and a conceptual framework. International Business Review, 26, 164-175.

Carter, L. \& Belanger, F. (2005). The utilization of e-government services: citizen trust, innovation and acceptance factors. Information Systems Journal, 15, 5-25.

Cyr, D. (2014). Return visits: a review of how Web site design can engender visitor loyalty. Journal of Information Technology, 29(1), 1-26.

Danila, R \& Abdullah, A. (2014) User's satisfaction on e-government services: An integrated model. Procedia-Social and Behavioral Sciences, 164, 575 - 582.

Davis, F. D. (1993). User acceptance of information technology: system characteristics, user perceptions and behavioral impacts. International Journal of Man-Machine Studies, 38, 475-487.

Deakins, E. Dillon, S. Al Namani, H. \& Zhang, C. K. (2010). Local e-government impact in China, New Zealand, Oman, and the United Kingdom. International Journal of Public Sector Management 23(6), 520-534.

DeLone, W. H., \& McLean, E. R. (2003). The DeLone and McLean model of information systems success: A ten-year update. Journal of Management Information Systems, 19(4), 9-30.

Flavian, C., \& Guinaliu, M. (2006). Consumer Trust, Perceived Security and Privacy Policy, Three Basic Elements of Loyalty to a Web Site. Industrial Management and Data Systems, 106(5), 601-620.

Gorla, N., Somers, T. M. \& Wong, B. (2010). Organizational impact of system quality, information quality, and service quality. The Journal of Strategic Information systems, 19, 207-228.

Harfouche, A., \& Robbin, A. (2012). Inhibitors and Enablers of Public E-Services in Lebanon. Journal of Organizational and End User Computing, 24(3), 45-68. 
Hong, J., Tai, K., Hwang, M., Kuo Y. \& Chen, J. (2018). Internet cognitive failure relevant to users' satisfaction with content and interface design to reflect continuance intention to use government e-learning system. Computers in Human Behavior, 66, 353-362.

Hong, W., Chan, F. K. Y., Thong, J. Y. L., Chasalow, L. C., \& Dhillon, G. (2014). A Framework and Guidelines for Context-Specific Theorizing in Information Systems Research. Information Systems Research, 25(1), 111-136.

Jacoby, J, Kaplan, L. B. (1972). The components of perceived risk. In: Venkatesan M, (Ed.) Advances in consumer research. Chicago: Association for Consumer Research.

Klein, H. K. \& Myers, M. (2001). A classification scheme for interpretive research in information systems. Chapter IX, p. 219-238, in Qualitative research in IS: Issues and trends, 2001, - books.google.com

Kurfalı, M., Arifo, A., Tokdemir, G., \& Paçin Y. (2017). Adoption of e-government services in Turkey. Computers in Human Behavior, 66, 168-178.

Lai, I. K. W. \& Shi, G. (2015). The Impact of Privacy Concern in the Consumer Acceptance of Mobile Instant Messaging and Social Network Integration Platform. International Journal of Mobile Communications, 13(6), 641-669.

Lee, M. (2009). Factors influencing the adoption of internet banking: An integration of TAM and TPB with perceived risk and perceived benefit. Electronic Commerce Research and Applications 8, 130-141.

Martins, C., Oliveira, T. \& Popovic, A. (2014). Understanding the Internet banking adoption: A unified theory of acceptance and use of technology and perceived risk application. International Journal of Information Management, 34, 1-13.

Nam, T. (2014). Determining the type of e-government use. Government Information Quarterly, 31, 211-220.

OECD (2003). The e-Government Imperative. OECD publications, France.

Oliver, R. L. (1980). A cognitive model for the antecedents and consequences of satisfaction. Journal of Marketing Research, 17(4), 460-469.

Pieron, T. M. \& Smith, J. N. (2017). Selection of Privacy Enhanced Communication: An Extension of The UTAUT2 Theory. Proceedings of the AMCIS Conference, aisel.aisnet.org

Preibusch, S. (2015). Privacy Behaviors After Snowden. Communication of the ACM, 58(5), 48-55.

Rana, N. P. \& Dwivedi, Y. K. (2015). Citizen's adoption of an e-government system: Validating extended social cognitive theory (SCT). Government Information Quarterly, 32, 172-181.

Rana, N. P. \& Dwivedi, Y. K. Williams, M. D. \& Weerakkody, W. (2015). Investigating success of an e-government initiative: Validation of an integrated IS success model. Information Systems Frontier, 17, 127-142.

Rouibah, K. Lowry, P., \& Hwang, Y. (2016). The effects of perceived enjoyment and perceived risks on trust formation and intentions to use online payment systems: New perspectives from an Arab country. Electronic Commerce Research and Application, 19, 33-43.

Rouibah, K., \& Al-Qirim, N. (2017). Factors Affecting Social Ecommerce Adoption in An Arab Country: Findings From a Qualitative Study. Issue in Information Systems, 18(2), 123-135.

Rouibah, K. (2008). Social Usage of Instant Messaging by individuals outside the workplace in Kuwait: A structural Equation Model. IT \& People, 21(1), 34-68.

Rouibah, K., Lowry, P. B., \& Al-Mutairi, L. (2015). B2C Systems Success Dimensions: Testing a Modified DeLone \& McLean IS Success Model in Kuwait in an E-Commerce Context. Journal of Global Information Management, 23(3), 41-70. 
Salem, A. A. R. (2016). The Potential Advantages of Implementing e-Government as well as Factors on Such Adoption. International Business Management, 10(03), 292-300.

Sang, S. Lee, J.-D., \& Lee, J. (2009). E-government adoption in ASEAN: the case of Cambodia. Internet Research, 19, $517-534$.

Shalini, R. T. (2009). Are Mauritians ready for e-Government services? Government Information Quarterly, 26, 536539.

Srivastava, S. C., \& Teo, T. S. H. (2005). Citizen Trust Development for E-Government Adoption: Case of Singapore. In: Proceedings of the Ninth Pacific Asia Conference on Information Systems, PACIS 2005.

The World Bank Group (2002). EGovernment Definition [Internet], Available from: http://www1.worldbank.org/publicsector/egov/definition.htm>

United Nations (2010). United Nations E-Government Survey (2010).

Veeramootooa, N. Nunkoob, R., \& Dwivedie, Y. K. (2018). What determines success of an e-government service? Validation of an integrative model of e-filing continuance usage. Government Information Quarterly, 35(2), 161-174.

Wang, H., \& Lo, J. (2010). Exploring Citizens' Intention to Use Government Websites in Taiwan: An Empirical Study. iiWAS '10 Proceedings of the $12^{\text {th }}$ International Conference on Information Integration and Web-based Applications \& Services, 524-531.

Wang, Y.-S., \& Liao, Y.-W. (2008). Assessing e-government systems success: A validation of the DeLone and McLean model of information systems success. Government Information Quarterly, 25(4), 717-733.

Warkentin, M. Sharma, S. Gefen, D., Rose, G. M. \& Pavlou, P. (2018). Social identity and trust in internet-based voting adoption. Government Information Quarterly, 35(2), 195-209.

Westin, A. F. (1967). Privacy and freedom. New York, NY, USA: Atheneum.

Yang, Q. Pang, C., Liu, L. Yen, D. C. \& Tarn, J. M. (2015). Exploring consumer perceived risk and trust for online payments: An empirical study in China's younger generation. Computers in Human Behavior, 50, 9-24.

Zhao, F. Scavarda, A.S. \& Waxin, M. (2012). Key issues and challenges in e-government development: An integrative case study of the number one eCity in the Arab world. Information Technology \& People, 25(4), $395-422$.

Ziemba, E. Papaj, T. Żelazny, R. \& Jadamus-Hacura, M. (2016). Factors Influencing The Success Of E-Government, Journal of Computer Information Systems, 56(2), 156-167. 